\title{
Tear and serum antibody levels in ocular herpetic infection: diagnostic precision of secretory $\operatorname{IgA}$
}

\author{
PETER D FOX,' PENG T KHAW,' BRIAN W McBRIDE, ' JAMES I McGILL,' \\ AND KEVIN A WARD \\ From 'Southampton Eye Hospital, Wilton Avenue, Southampton SO9 4XW, and the 'Department \\ of Microbiology, Southampton University Medical School, Tremona Road, Southampton SO9 $4 X Y$
}

SUMmaRY A sensitive enzyme linked immunosorbent assay (ELISA) was developed to evaluate the potential of herpes simplex virus (HSV) specific antibodies in the diagnosis of herpetic eye infection. The presence of HSV specific secretory $\operatorname{IgA}(\operatorname{sIgA})$ in tears was found to be diagnostic of infection. However, serum and tear HSV specific IgG and IgA were not considered reliable indicators of active infection.

Herpes simplex (HSV) virus is an important cause of ocular infection and is acknowledged as a major cause of corneal blindness in developed countries. It is therefore important accurately to diagnose and treat herpetic eye disease. The diagnosis is often made on pathognomonic clinical findings such as corneal dendritic ulcers and less frequently cutaneous lid vesicles. ' However, herpetic eye infections may present non-specifically as an acute follicular conjunctivitis or punctate keratoconjunctivitis, ${ }^{2}$ in which the differential diagnosis includes adenoviral infections and trachoma inclusion conjunctivitis. HSV ocular infection has been estimated to account for $21 \%$ of patients attending an ophthalmic casualty department with an acute conjunctivitis. ${ }^{3}$

The laboratory diagnosis of HSV infections is usually made on tissue culture, but this technique depends on the presence of viable virus and may be inhibited by antivirals and antibodies. Alternatively the measurement of HSV specific antibodies has been suggested as a diagnostic parameter. ${ }^{3-5}$ However, HSV specific IgG and IgA antibodies in serum are present in the majority of the adult population, ${ }^{67}$ and levels of antibodies in tears may be falsely elevated by transudation of serum antibodies in to the lacrimal fluid of an inflamed eye. ${ }^{8}$ The detection of secretory $\operatorname{IgA}(\operatorname{sIgA})$ in tears should avoid these problems, as it is locally produced and is not present in serum. ${ }^{8}$ Tear $\operatorname{sIgA}$ is a dimeric IgA synthesised by subepithelial plasma cells in the lacrimal gland,

Correspondence to James I McGill, FRCS, Southampton Eye Hospital, Wilton Avenue, Southampton SO9 4XW. which then binds to receptors on epithelial cells and is transported across the cell to the duct. ${ }^{10}$ The secretory component in $\operatorname{sIgA}$ is derived from the cell receptor and binds to the $\mathrm{J}$ chain of dimeric IgA. ${ }^{10} \mathrm{~A}$ radioimmunoassay for ' $I$ IgA specific to HSV has previously been described," and, although it has not been assessed in a clinical context, the authors considered that the assay had diagnostic potential. ${ }^{5}$

In this paper we describe a sensitive method for the detection of HSV specific antibodies (IgG, IgA, and $\operatorname{sig} \mathrm{A}$ ) by enzyme linked immunosorbent assay (ELISA) and compare the response in a variety of clinical presentations of HSV ocular infections.

\section{Materials and methods}

Fifty-six patients attending the Casualty Department at Southampton Eye Hospital with suspected acute viral conjunctivitis during the period June to December 1984 were included in this study. All patients were examined on a Haag-Streit slit-lamp and were assigned to one of three clinical categories: (i) acute follicular conjunctivitis or keratoconjunctivitis; (ii) corneal dendritic ulcers; and (iii) orofacial herpetic vesicles with a conjunctivitis. Nineteen controls were selected from patients with an inflamed eye not due to infection.

Tear samples from the lower fornices of affected eyes were collected into $0.7 \mathrm{~mm}$ internal diameter capillary tubes. These tubes, which contained an inner filament to increase capillarity (Kwik-fil glass capillaries: Clark Electromedical Instruments), were bent into a hockey-stick shape to facilitate collection. 
The sample (usually 5 to $20 \mu \mathrm{l}$ ) was expelled into a preweighed conical plastic tube and transported to the laboratory, where it was diluted with an equal volume of glycerol and stored in liquid state at $-20^{\circ} \mathrm{C}$. By this method it was usually possible to collect adequate volumes for analysis from an inflamed eye.

Conjunctival swabbings for virus isolation were taken from the lower fornix and placed in viral transport medium (HEPES buffered HBSS containing $10 \%$ fetal calf serum and antibiotics). HEp-2 and MRC- 5 cells were inoculated, incubated at $37^{\circ} \mathrm{C}$, and examined regularly for the presence of cytopathic effect. HSV isolates were identified by electron microscopy.

Blood samples were collected by venepuncture at the first presentation to the Casualty Department. Sera were separated and stored at $+4^{\circ} \mathrm{C}$ with $0.05 \%$ sodium azide. All samples were transported to the laboratory immediately after collection.

Serum and tear antibody levels were measured by indirect ELISA. 96-well high activated PVC plates (Flow Laboratories) were coated with excess antigen by overnight incubation with HSV antigen in $0.1 \mathrm{M}$ sodium carbonate buffer, $\mathrm{pH} 9 \cdot 6$. The antigen was prepared by extraction of HSV type 1 infected Chang conjunctival cells with $1 \%(\mathrm{w} / \mathrm{v})$ sodium cholate. Serum and tear samples $(1 \mu \mathrm{l})$ were diluted 1:100 in $5 \%$ normal rabbit serum with $0.05 \% \quad(w / v) \quad W l$ detergent (Sigma) and $0.9 \% \mathrm{NaCl}$ and incubated in the antigen-coated wells for three hours at $37^{\circ} \mathrm{C}$. Antigen specific IgG, IgA, and $\operatorname{sIgA}$ were detected by anti-IgG, anti-IgA, and antisecretory component horseradish peroxidase (HRPO) conjugates (Dakopatts) at respective dilutions of 1:2000, 1:2000, and $1: 100$ as above. After 30 minutes' incubation at $37^{\circ} \mathrm{C}$ the enzyme substrate $3,3^{\prime}, 5,5^{\prime}$-tetramethylbenzidine (TMB, Miles) was added ${ }^{12}$ and the reaction allowed to proceed for 5 minutes. The enzyme reaction was stopped by the addition of $2 \mathrm{M} \mathrm{H}_{2} \mathrm{SO}_{4}$ and the absorbance $450 \mathrm{~nm}$ measured (Titertek Multiskan, Flow Laboratories).

Virus specific immunoglobulin $\mathrm{G}$ and $\mathrm{A}$ concentrations were calculated from a standard curve of absorbance ${ }_{450} \mathrm{~nm}$ plotted against immunoglobulin class. This was constructed by incubation of anti-IgG and anti-IgA HRPO conjugates, as described above, in plates coated with dilutions of purified IgG and IgA radiolabelled with ${ }^{125}$ I to a known specific activity with the solid phase chloramine-T reagent, Iodobeads (Pierce). The amount of solid phase immunoglobulin standard at each dilution was measured using a gamma counter. Each immunoglobulin class specific conjugate showed no detectable cross reactivity with the other antibody class. This method permitted quantitation of IgG levels over the range $0 \cdot 2-14 \cdot 0$ $\mu \mathrm{g} / \mathrm{ml}$ and of IgA levels in the range $0 \cdot 5-26 \cdot 0 \mu \mathrm{g} / \mathrm{ml}$. (SI conversion: $\mu \mathrm{g} / \mathrm{ml}=\mathrm{mg} / \mathrm{l}$.)

Secretory IgA levels in tears were expressed in absorbance units, as no purified secretory component was available to construct a standard curve. Values were considered positive if they fell outside 2 standard deviations of the mean background level as measured in the corresponding sera. No crossreactions with purified $\operatorname{IgA}, \operatorname{IgG}$, or IgM could be detected by ELISA.

\section{Results}

Clinical presentation. Of the 56 patients included in this study 19 presented with a follicular conjunctivitis or punctate keratoconjunctivitis, 31 with corneal dendritic ulcers, and 6 with an inflamed eye in conjunction with orofacial herpetic vesicles. The 19 controls included 15 postoperative patients (eight cataracts, four glaucoma, three retinal detachment), two traumatic abrasions, one lens induced uveitis, and one glaucoma patient on treatment.

Tissue culture. HSV was isolated from 19 of the 56 patients, of whom 16 had dendritic ulcers, two had orofacial herpetic vesicles with a conjunctivitis, and one had a follicular conjunctivitis.

Serum and tear HSV specific $\operatorname{Ig} G$ and $\operatorname{Ig} A$. HSV specific IgG and IgA was measured by ELISA in serum from 48 patients and 19 controls and in tears from 49 patients and 19 controls. These results are displayed in Fig. 1, analysed by clinical category.

High levels of HSV specific IgG and IgA were detected in sera from all groups, including the controls. Serum HSV specific IgG levels were significantly higher in the dendritic group $(p<0.005)$ and the orofacial vesicles/conjunctivitis group $(p=0.0095)$ when compared with the controls. Similarly HSV specific serum IgA levels were significantly higher in the dendritic group $(p=0.007)$ and the orofacial vesicles/conjunctivitis group ( $p=0.004)$ than the controls. Both HSV specific IgG and IgA levels in serum were similar in the controls and the follicular conjunctivitis group.

Tear samples from all groups contained HSV specific IgG and IgA with no significant difference between the controls and any of the clinical groups. HSV specific IgG and IgA were never present at higher levels in tears than in the corresponding sera.

Tear antibody levels were analysed by day of presentation among patients in whom either HSV was isolated by tissue culture or $\operatorname{sgA}$ detected. The levels of tear IgA were significantly higher $(p=0.05)$ after the second day of symptoms when compared with those presenting earlier. No such rise in tear IgG levels with time could be shown.

$H S V$ specificsIgA in tears. Tear samples of sufficient 

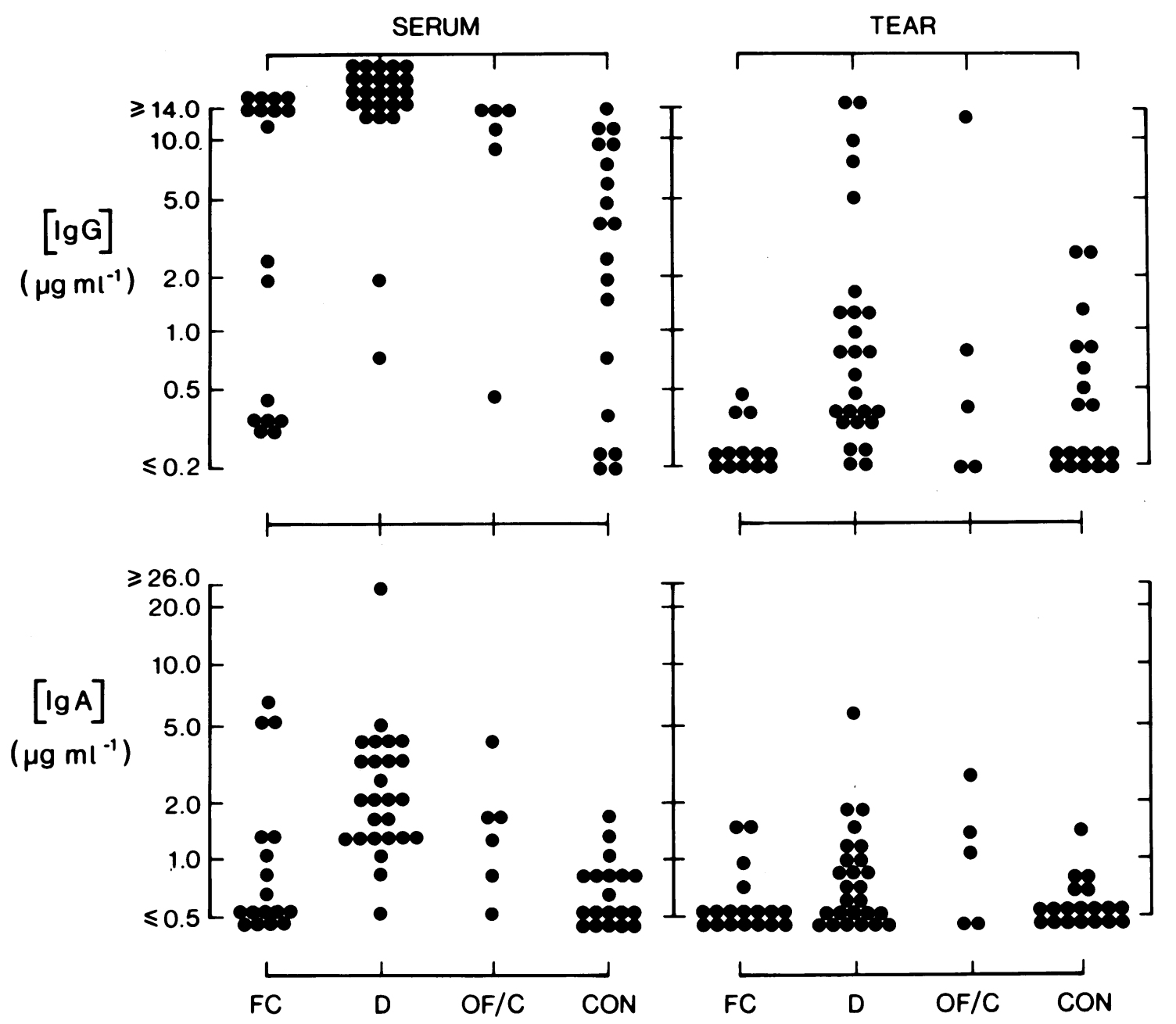

CLINICAL GROUP

Fig. 1 Serum and tear levels of HSV specific IgG and IgA analysed by clinical group. FC = follicular conjunctivitis. $\mathrm{D}=$ dendritic ulcers. $\mathrm{OF} / \mathrm{C}=$ orofacial vesicles/conjunctivitis. $\mathrm{CON}=$ controls.

volumes to measure $\operatorname{sIgA}$ were available from 53 patients and 19 controls. HSV specific sIgA was detected in 20 of the 53 patients, of whom 12 were HSV isolate negative. Secretory IgA was not detected in any of the control group (Fig. 2).

In the dendritic ulcer group 16 out of the 29 tear samples contained SIgA. Of these, 10 were HSV isolate negative by tissue culture. A total of 26 of the 31 patients in the dendritic group were either HSV isolate positive or had detectable HSV specific SIgA. In the orofacial herpetic vesicles/conjunctivitis group tears from three of the six patients contained HSV specific SIgA, of which one was HSV isolate negative.
HSV specific sIgA was found in one patient in the follicular conjunctivitis group; this patient was HSV isolate negative.

Secretory IgA levels were correlated against duration of symptoms in 29 patients in whom either HSV was isolated by tissue culture or $\operatorname{SIgA}$ was detected (Fig. 3). Fourteen of the 19 isolates of HSV were obtained from patients with symptoms of seven days' duration or less. Of the five isolates with symptoms of more than seven days three had been treated with topical steroids prior to presentation to the Eye Hospital. Eight patients with no detectable sIgA were HSV isolate positive. Of these, seven presented 


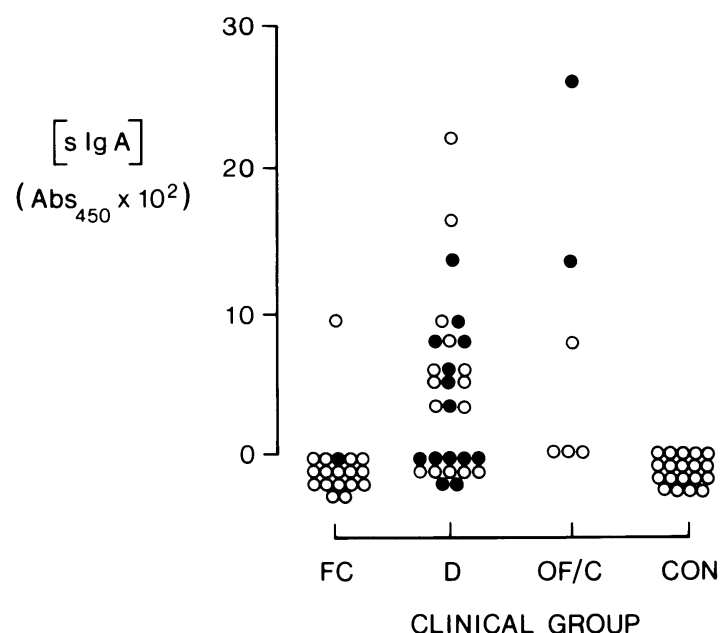

Fig. $2 H S V$ specific secretory $\operatorname{Ig} A(s \operatorname{Ig} A)$ levels in tears analysed by clinical group. $\mathrm{FC}=$ follicular conjunctivitis. $\mathrm{D}=$ dendritic ulcers. $\mathrm{OF} / \mathrm{C}=$ orofacial vesicles/conjunctivitis . $\mathrm{CON}=$ controls. Cases showing positive $(\bullet)$ or negative $(O)$ virus isolation.

in the first four days of symptoms and one presented at day 14 but had received topical steroids prior to presentation.

Follow-up tear samples, taken from six to 30 days after the first sample, were available from seven patients. Six of these samples contained HSV specific sIgA on presentation and remained detectable on follow-up. Two of these patients were HSV isolate

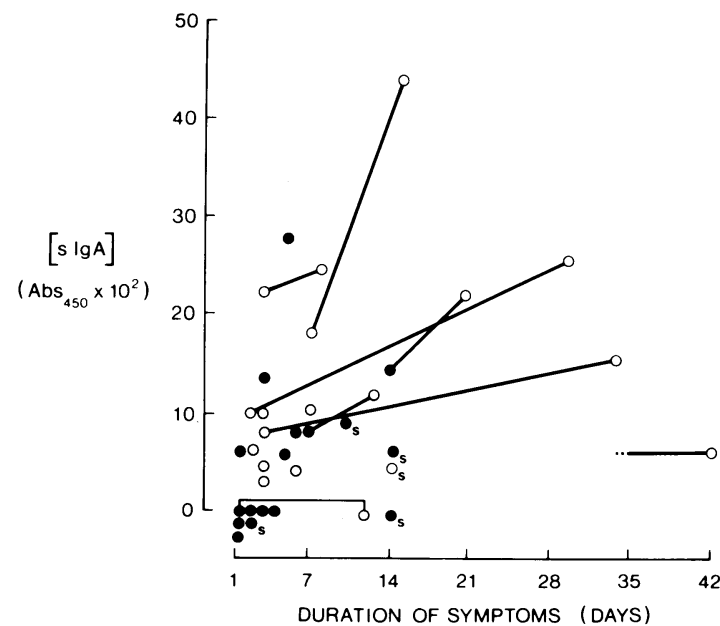

Fig. 3 Analysis of HSV specific secretory $\operatorname{IgA}(\mathrm{s} \operatorname{IgA})$ levels in tears according to duration of symptoms at presentation and on follow-up (paired values). One unpaired convalescent tear sample was obtained at day 42. Positive or negative virus isolation denoted by $(\bullet)$ or $(0)$ respectively. $\mathrm{s}=$ Prior application of topical steroids. positive on presentation, but tissue culture was consistently negative on follow-up. One tear sample taken at day 42 from a patient with a healing dendritic ulcer contained SIgA, but HSV was not isolated (Fig. $3)$.

\section{Discussion}

In this study HSV specific SIgA was detected in the tears of 19 of the 37 patients with characteristic herpetic lesions (dendritic ulcers or orofacial vesicles/ conjunctivitis). In contrast none of the controls and only one of the 19 patients with a follicular conjunctivitis had detectable HSV specific SIgA in their tears. This suggests that the presence of HSV specific SIgA is indicative of herpetic infection. Secretory IgA was generally detected only in patients presenting after the first few days of symptoms, from whom HSV was usually not isolated on tissue culture. The detection of HSV specific sIgA in conjunction with virus isolation increased the laboratory diagnosis of HSV eye infections to $55 \%$ of the patients in our study, compared with $34 \%$ by tissue culture alone. In particular a laboratory diagnosis of HSV infection could be made in $84 \%$ of the dendritic ulcer group.

Although levels of HSV specific serum IgG and IgA were significantly higher in both the dendritic ulcer group and the orofacial vesicles/conjunctivitis group than in the control group, the presence of high antibody levels in some controls with no evidence of herpetic eye infection indicates that these parameters are not diagnostically reliable. The rise in tear $\operatorname{IgA}$ levels, though not IgG, presumably reflects local production of $\operatorname{sIgA}$. However, the overall similarity in tear IgA and IgG levels between the clinical groups and the controls confirms earlier suggestions that these values are not diagnostic, possibly owing to transudation of serum antibodies. The detection of tear IgG and IgA in over half of those controls with detectable serum antibodies is evidence of transudation of antibodies into an inflamed eye.

Four patients with a laboratory diagnosis of HSV infection had low levels of serum IgG specific to HSV on presentation, which suggests that these were primary herpetic infections. Two of these patients had dendritic ulcers, which may develop in primary herpetic eye infection, ${ }^{2}$ and two presented with a follicular conjunctivitis. A follow-up serum sample in one of the patients with a dendritic ulcer showed a rise in levels of HSV specific IgG (from 1.5 to 9.0 $\mu \mathrm{g} / \mathrm{ml}$ ), which was associated with a concurrent rise in HSV specific IgM (from 4.5 to $7.0 \mu \mathrm{g} / \mathrm{ml}$ ). (SI conversion: $\mu \mathrm{g} / \mathrm{ml}=\mathrm{mg} / \mathrm{l}$.)

Four patients presented with corneal dendritic ulcers following the use of topical steroids, which are known to enhance dendritic ulceration..$^{13}$ It is of 
interest that these patients had lower sIgA levels, and $\mathrm{HSV}$ was isolated later in the course of the disease, in comparison with the rest of the patients with evidence of active HSV infection.

We conclude that the detection of HSV specific tear SIgA by ELISA in patients with suspected viral conjunctivitis is a valuable adjunct to virus isolation in the diagnosis of herpetic eye infection. HSV is usually isolated in the first few days of symptoms, when sIgA levels are low. The rise in HSV specific $\operatorname{sIgA}$ thereafter permits a laboratory diagnosis to be made when virus is usually not recovered on tissue culture, in particular following the use of antivirals. The detection of HSV specific sIgA by enzyme linked immunosorbent assays provides a rapid and sensitive diagnostic assay without the need for expensive laboratory equipment or radioisotope handling facilities.

We are grateful to Professor $P \mathrm{~J}$ Watt for support and advice in this work, to Mr M J Absolon, Mr I H Chisholm, Mr A R Elkington, and Mr C B Walker for allowing us to study their patients, and to Sara Hipwell for the typescript.

This work was supported by grant number $12213 / 15$ from the Wellcome Trust.

\section{References}

1 Jones BR. The management of ocular herpes. Trans Ophthalmol Soc UK 1959; 79: 425-37.

2 Darougar S, Hunter PA, Viswalingham M, Gibson JA, Jones BR. Acute follicular conjunctivitis and keratoconjunctivitis in London. Br J Ophthalmol 1978; 62: 843-9.
3 Wishart PK, James C, Wishart MS, Darougar S. Prevalence of acute conjunctivitis caused by chlamydia, adenovirus, and herpes simplex virus in an ophthalmic casualty department. $\mathrm{Br} \mathrm{J}$ Ophthalmol 1984; 68: 653-5.

4 Krichevskaya GI, Zaitseva NS, Kainarbaeva KA, Basova NN, Vinogradova VL. The use of a passive haemagglutination test (PHA) in the diagnosis of viral eye diseases. Graefes Arch Klin Exp Ophthalmol 1980; 214: 239-44.

5 Pedersen B, Moller Andersen S, Klauber A, Ottovay E, Prause JU, Zhong C, Norrild B. Secretory IgA specific for herpes simplex virus in lacrimal fluid from patients with herpes keratitis -a possible diagnostic parameter. Br J Ophthalmol 1982; 66: 648-53.

6 Vestergaard BF, Hornsleth A, Nodskov Pedersen S. Occurrence of herpes and adenovirus antibodies in patients with carcinoma of the cervix uteri. Cancer 1972; 30: 68-74.

7 Fricdman MG, KimmelN. Herpessimplex virus specific immunoglobulin A: detection in patients with primary or recurrent herpes infections and in healthy adults. Infect Immun 1982; 37: 374-7.

8 McClellan BH, Whitney CR, Newman LP, Allansmith MR. Immunoglobulins in tears. Am J Ophthalmol 1973; 76: 89-101.

9 Franklin RM, Kenyon KR, Tomasi TB. Immunohistologic studies of human lacrimal gland: localisation of immunoglobulins, secretory component and lactoferrin. J Immunol 1973; 110: 984-92.

10 Watt PJ, Ward KA. Mucosal immunity and the cyc. Trans Ophthalmol Soc UK 1985; 104: 367-73.

11 Norrild B, Pedersen B, Moller-Andersen S. Herpes simplex virus specific secretory $\operatorname{IgA}$ in lacrimal fluid during herpes keratitis. Scand J Clin Lab Invest 1982; 42: 29-33.

12 Bos ES, Van der Doelen AA, Van Rooy N, Schuurs AHWN. 3, 3', 5, 5'-tetramethylbenzidine as an Ames test negative chromogen for horseradish peroxidase in enzyme immunoassay. $J$ Immunoassay 1981; 2: 187-204.

13 Patterson A, Jones BR. The management of ocular herpes. Trans Ophthalmol Soc UK 1967; 87: 59-84.

Accepted for publication 6 December 1985. 